\title{
Assessment of Existing Bridge's Beam Bending Stiffness Using Crack Characteristics
}

\author{
Donglian Tan \\ Shanghai Institute of Technology, Shanghai, China \\ Email: td1021@126.com
}

How to cite this paper: Tan, D.L. (2020) Assessment of Existing Bridge's Beam Bending Stiffness Using Crack Characteristics. Engineering, 12, 82-89.

https://doi.org/10.4236/eng.2020.122008

Received: January 9, 2020

Accepted: February 7, 2020

Published: February 10, 2020

Copyright $\odot 2020$ by author(s) and Scientific Research Publishing Inc. This work is licensed under the Creative Commons Attribution International License (CC BY 4.0).

http://creativecommons.org/licenses/by/4.0/

\begin{abstract}
At present, the bearing capacity evaluation is mainly based on load detection, which requires closed traffic and has certain risks. With the increase of service time, the cracks of reinforced concrete beam bridge will gradually develop and the stiffness will reduce, resulting in the decrease of bearing capacity. Therefore, in this paper, the calculation of stiffness reduction coefficient by using crack characteristic parameters, which provides basic data for bearing capacity evaluation, has been studied. In this paper, using regression analysis through fracture characteristics of four model beam observation and test load-displacement curve characteristic parameters, crack flexural rigidity of the beam bridge relationship has been set up. The qualitative assessment based appearance of cracks in the structure of checks has been converted to quantitative assessment. And compared with the test results of a real bridge, comparative results show that the assessment is objective and reliable. It makes the assessment more objective and scientific. A new way of Quantitative assessment of the structural performance has been provided for a large number of existing reinforced concrete beam bridge.
\end{abstract}

\section{Keywords}

Beam Bridge, Crack Characteristics, Bending Stiffness, Assessment

\section{Introduction}

The evaluation methods commonly used in the past include empirical method and load test method, which are highly subjective, while the load test method is costly and has certain risks [1] [2] [3]. It is a common problem for reinforced concrete Bridges to have cracks in service. After the cracking, the bending stiffness of the beam with the cracked section is bound to decrease, which reduces the bearing capacity of the structure. Therefore, reasonable structural bearing 
capacity evaluation should be carried out for further treatment measures [4] [5] [6] [7]. In literature [8], the calculation model established by constructing damage element is used to evaluate the mechanical performance of prestressed concrete structure in service, which is not convenient for general managers to use. A method to evaluate the bearing capacity by deflection and crack height is proposed in literature [9] [10]. The deflection needs long-term observation, and it is difficult to ensure its continuity. If the crack height is not enough to evaluate the bearing capacity, the crack width, which can best represent the structural performance, is not taken into account. Based on the observation results of characteristic parameters of cracks of four pieces of model test beams [11], this paper established the relationship between characteristic parameters of cracks and flexural stiffness through regression analysis of characteristic parameters of cracks and load-displacement curves reflecting stiffness, providing a new method for quantitative evaluation of in-service reinforced concrete beam bridges.

\section{Crack Characteristic Parameters}

The crack characteristic parameter is the appearance reflection of the structure state. In general, the statistical parameters of crack characteristics of beam include average crack height $h_{c r}$, Crack spacing $l_{c r}$, Maximum crack width $w_{\max }$ and the like.

$h_{c r}$ denotes the degree to which the concrete in the tension zone exits the work, implying the concrete area in the compression zone. $w_{\max }$ indicates the development of cracking, and implies the beam deformation curvature. $l_{c r}$ represents the number of cracks in the beam section. The bending stiffness reduction factor is expressed as $\beta$.

\section{Brief Introduction of Test}

The specimens are 4 rectangular beams. The size of its cross section is $150 \mathrm{~mm} \times$ $250 \mathrm{~mm}$. the length of the beam is $2700 \mathrm{~mm}$. The span is $2410 \mathrm{~mm}$. The concrete grade of the specimen is C30. The tension reinforcement grade is HPB300, whose diameter is $12 \mathrm{~mm}$. At three points, the specimen is loaded in stages by concentrated force. The section size, loading mode and strain measuring point layout of the specimen are shown in Figure 1. Strain and mid-span deflection of the test point are measured after each step loading.

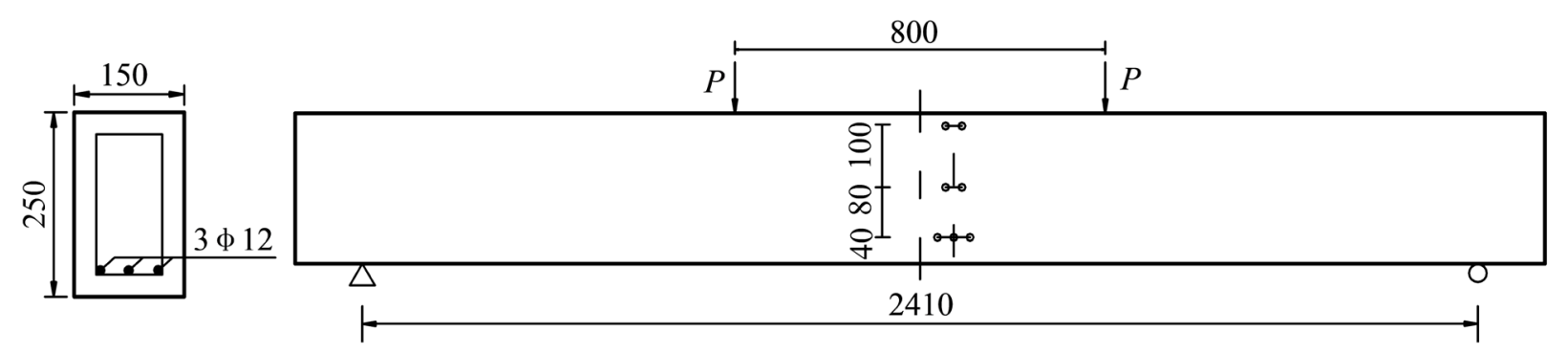

Figure 1. Beam section, loading method and layout of strain measuring. 


\section{Relationship between $w_{\max }$ and $\beta$}

In the process of loading, the deflection of the beam will increase with the increase of the load, and its stiffness will change with each level of load. Therefore, according to the load-deflection curve, the flexural stiffness reduction coefficient is calculated by the formula $\beta=K_{i} / K_{1}$.

Let $K_{1}$ be the initial stiffness of the beam in the elastic stage and $K_{i}$ be the stiffness at the $i$ th loading. Where, $K_{1}$ is the tangent stiffness and $K_{i}$ is the secant stiffness, then the ratio of the ith secant stiffness to the tangent stiffness is the reduction coefficient of bending stiffness of the beam

With the increase of loading load, the bending stiffness of beam body decreases after cracks appear. The mid-span deflection and stiffness reduction coefficient of specimens under various loads in the loading process are shown in Table 1, and the statistical data of beam body crack width are shown in Table 2.

Table 1. The midspan deflection and reduction factor under load level.

\begin{tabular}{cccccccccccccc}
\hline & Sample 1 & \multicolumn{3}{c}{ Sample 2 } & \multicolumn{3}{c}{ Sample 3 } & & \multicolumn{3}{c}{ Sample 4 } \\
\hline $\begin{array}{c}\text { class of } \\
\text { loading } \\
/ \mathrm{kN}\end{array}$ & $\begin{array}{c}\text { deflection } \\
/ \mathrm{mm}\end{array}$ & $\begin{array}{c}\text { stiffness } \\
\text { reducing } \\
\text { factor }\end{array}$ & $\begin{array}{c}\text { class of } \\
\text { loading } \\
/ \mathrm{kN}\end{array}$ & $\begin{array}{c}\text { deflection } \\
/ \mathrm{mm}\end{array}$ & $\begin{array}{c}\text { stiffness } \\
\text { reducing } \\
\text { factor }\end{array}$ & $\begin{array}{c}\text { class of } \\
\text { loading } \\
/ \mathrm{kN}\end{array}$ & $\begin{array}{c}\text { deflection } \\
/ \mathrm{mm}\end{array}$ & $\begin{array}{c}\text { stiffness } \\
\text { reducing } \\
\text { factor }\end{array}$ & $\begin{array}{c}\text { class of } \\
\text { loading } \\
/ \mathrm{kN}\end{array}$ & $\begin{array}{c}\text { deflection } \\
/ \mathrm{mm}\end{array}$ & $\begin{array}{c}\text { stiffness } \\
\text { reducing } \\
\text { factor }\end{array}$ \\
\hline 20 & 1.50 & 1.00 & 20 & 2.10 & 1.00 & 20 & 2.10 & 1.00 & 20 & 1.92 & 1.00 \\
30 & 2.70 & 0.83 & 30 & 3.48 & 0.91 & 30 & 3.54 & 0.89 & 30 & 3.48 & 0.83 \\
40 & 4.56 & 0.66 & 40 & 3.30 & 1.27 & 40 & 4.80 & 0.88 & 40 & 4.50 & 0.85 \\
50 & 5.22 & 0.72 & 50 & 5.88 & 0.89 & 50 & 6.12 & 0.86 & 50 & 5.40 & 0.89 \\
60 & 6.78 & 0.66 & 60 & 7.80 & 0.81 & 60 & 8.10 & 0.78 & 60 & 6.78 & 0.85 \\
70 & 7.80 & 0.67 & 65 & 14.10 & 0.48 & 65 & 14.10 & 0.48 & 70 & 15.60 & 0.43 \\
80 & 22.20 & 0.27 & - & - & - & 68 & 20.52 & 0.35 & - & - & - \\
84 & 25.92 & 0.24 & - & - & - & - & - & - & - & - & - \\
\hline
\end{tabular}

Table 2. Crack width under each load level.

\begin{tabular}{cccccccc}
\hline \multicolumn{2}{c}{ Sample 1} & \multicolumn{2}{c}{ Sample 2} & \multicolumn{2}{c}{ Sample 3 } & \multicolumn{2}{c}{ Sample 4} \\
\hline $\begin{array}{c}\text { class of } \\
\text { loading/kN }\end{array}$ & $\begin{array}{c}\text { crack } \\
\text { width/mm }\end{array}$ & $\begin{array}{c}\text { class of } \\
\text { loading/kN }\end{array}$ & $\begin{array}{c}\text { crack } \\
\text { width/mm }\end{array}$ & $\begin{array}{c}\text { class of } \\
\text { loading/kN }\end{array}$ & $\begin{array}{c}\text { crack } \\
\text { width/mm }\end{array}$ & $\begin{array}{c}\text { class of } \\
\text { loading/kN }\end{array}$ & $\begin{array}{c}\text { crack } \\
\text { width/mm }\end{array}$ \\
\hline 20 & 0.02 & 20 & 0.10 & 20 & 0.04 & 20 & 0.04 \\
30 & 0.06 & 30 & 0.10 & 30 & 0.06 & 30 & 0.09 \\
40 & 0.10 & 40 & 0.10 & 40 & 0.10 & 40 & 0.15 \\
50 & 0.15 & 50 & 0.10 & 50 & 0.15 & 50 & 0.15 \\
60 & 0.15 & 60 & 0.40 & 60 & 0.18 & 60 & 0.17 \\
70 & 0.20 & 65 & 1.30 & 68 & 1.4 & 70 & 0.85 \\
80 & 0.90 & - & - & - & - & - & - \\
84 & 1.30 & - & - & - & - & - & - \\
\hline
\end{tabular}


Regression analysis was conducted based on the reduction coefficient of bending stiffness and corresponding crack width, and the regression curve was obtained as shown in Figure 2. The regression equation of bending stiffness reduction coefficient and crack height coefficient can be obtained:

$$
\beta=0.9937-1.10048 w_{\max }+0.46195 w_{\max }^{2}
$$

correlation index $R=0.73041$

\section{Relationship between $\boldsymbol{h}_{c r}$ and $\beta$}

The crack height $h_{c r}$ directly affects the moment of inertia of the effective section of the beam. With the development of the crack along the beam height, the neutral axis of the section moves up, and its bending stiffness decreases. Table 3 shows the statistical data of average crack height of beam body in the test loading process.

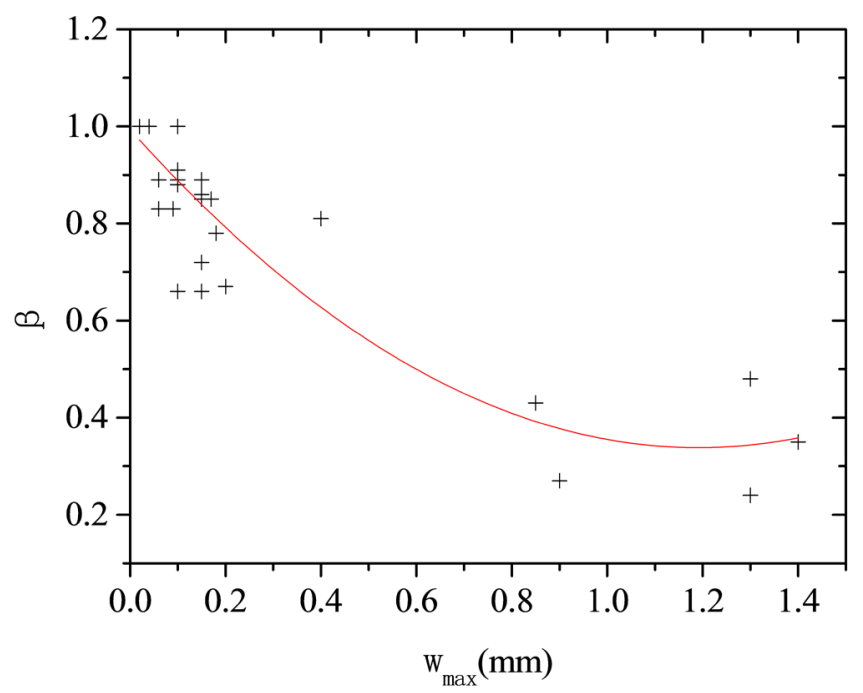

Figure 2. $\beta \sim w_{\max }$.

Table 3. The average height.

\begin{tabular}{cccccccc}
\hline \multicolumn{2}{c}{ Sample 1} & \multicolumn{2}{c}{ Sample 2} & \multicolumn{2}{c}{ Sample 3} & \multicolumn{2}{c}{ Sample 4} \\
\hline $\begin{array}{c}\text { class of } \\
\text { loading/kN }\end{array}$ & $\begin{array}{c}\text { average } \\
\text { height/cm }\end{array}$ & $\begin{array}{c}\text { class of } \\
\text { loading/kN }\end{array}$ & $\begin{array}{c}\text { average } \\
\text { height/cm }\end{array}$ & $\begin{array}{c}\text { class of } \\
\text { loading/kN }\end{array}$ & $\begin{array}{c}\text { average } \\
\text { height/cm }\end{array}$ & $\begin{array}{c}\text { class of } \\
\text { loading/kN }\end{array}$ & $\begin{array}{c}\text { average } \\
\text { height/cm }\end{array}$ \\
\hline 20 & 7.50 & 20 & 8.57 & 20 & 11.62 & 20 & 11.88 \\
30 & 11.94 & 30 & 12.67 & 30 & 14.57 & 30 & 14.31 \\
40 & 13.81 & 40 & 13.13 & 40 & 15.14 & 40 & 15.15 \\
50 & 15.31 & 50 & 13.75 & 50 & 15.29 & 50 & 16.00 \\
60 & 15.75 & 60 & 16.13 & 60 & 15.43 & 60 & 16.00 \\
70 & 16.50 & 65 & 18.00 & 68 & 16.36 & 70 & 17.15 \\
80 & 16.81 & - & - & - & - & - & - \\
84 & 20.13 & - & - & - & - & - & - \\
\hline
\end{tabular}


The relation curve between the average crack height and the reduction coefficient of bending stiffness of the beam body is drawn from Table 1 and Table 3, as shown in Figure 3.

In order to better study the relationship between crack development height and bending stiffness reduction coefficient crack height coefficient $H$ is introduced.

$$
H=h_{\text {cr }} / h
$$

where, $H$ is crack height coefficient; $h_{c r}$ is the average crack height of the beam body. $h$ is the height of beam section.

Thus, the regression diagram of reduction coefficient of flexural stiffness and crack height coefficient $H$ is obtained, as shown in Figure 4. Through regression analysis, the relationship between bending stiffness reduction coefficient and crack height coefficient $H$ is obtained:

$$
\beta=0.46406+3.22583 H-4.38153 H^{2}
$$

correlation index $R=0.63393$.

\section{Assessment Instance}

\subsection{Bridge Profile}

In this paper, the flexural stiffness of a real bridge with a reinforced concrete simply supported beam is evaluated by using the stiffness evaluation formula established in this paper. The bridge was built in the 1960s, 55 years after service. Because of environmental impact, materials aging, overload, traffic surge and route reconstruction and other reasons, it can't meet the requirements of the project. It needs to be evaluated for reinforcement and expansion. Now one of the $\mathrm{T}$ beams of the bridge is taken as an example for analysis. The concrete mark C20 of $\mathrm{T}$ beam and the steel bar model HRB335 are shown in this film. The beam section size is $8.80 \mathrm{~m} 0.80 \mathrm{~m} 0.75 \mathrm{~m}$, as shown in Figure 5 .

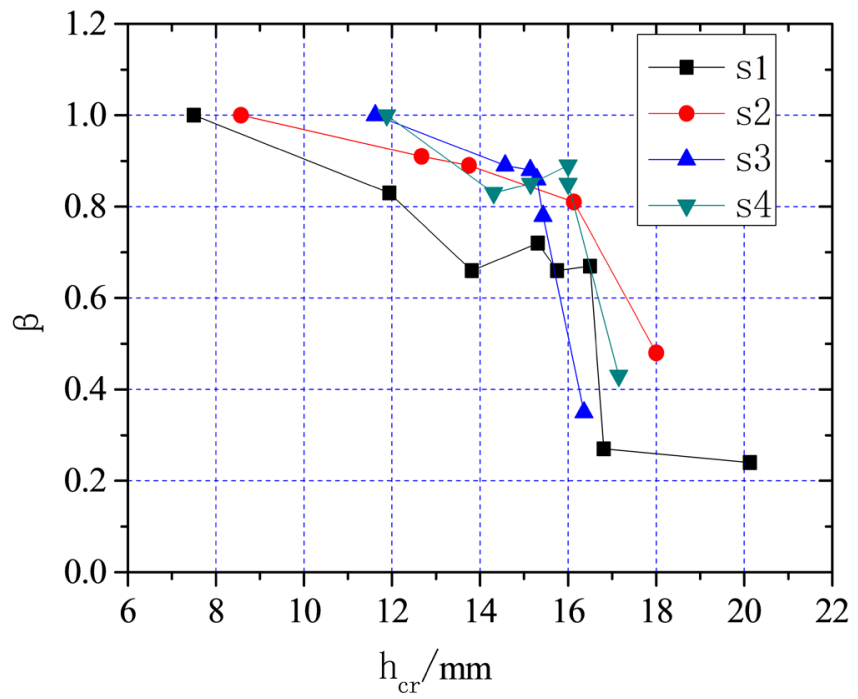

Figure 3. $\beta \sim h_{c r}$. 


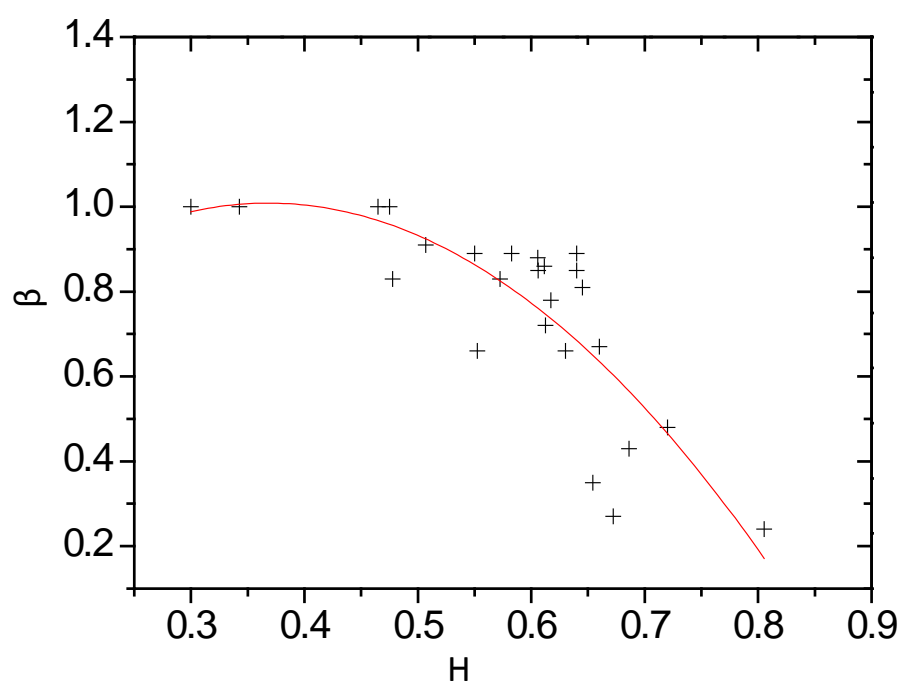

Figure 4. $\beta \sim H$.

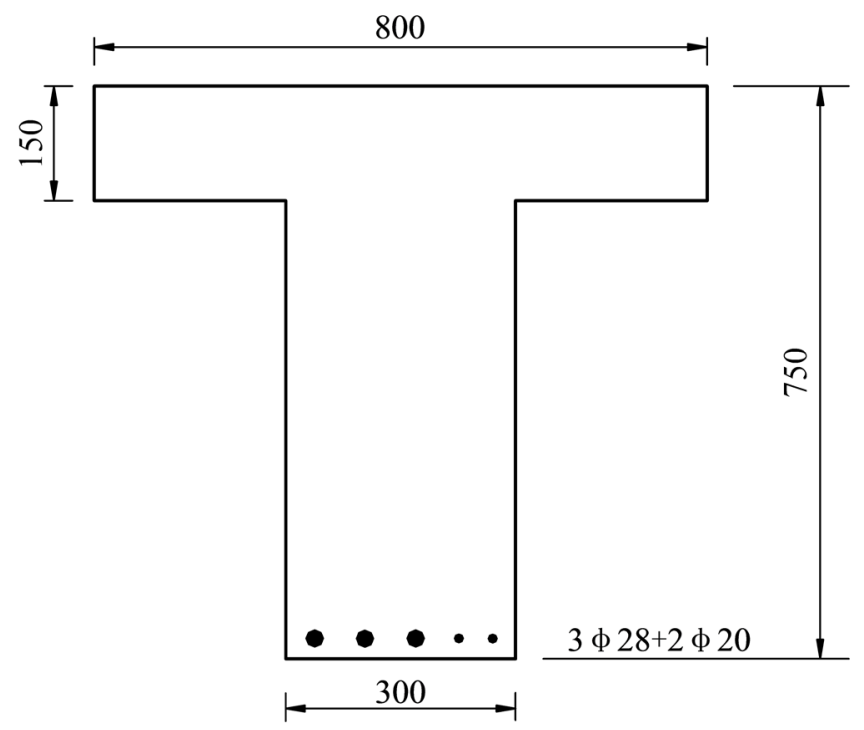

Figure 5. The size of T beam and layout of steel.

\subsection{Crack Inspection Results}

The crack condition of beam body is: there are 18 cracks in the beam body on both sides, the width of the widest crack is $0.6 \mathrm{~mm}$. Most of the cracks are concentrated within 1.2 meters of the beam end. The length of the 11 cracks is greater than $400 \mathrm{~mm}$. The average height of cracks was set at $420 \mathrm{~mm}$, and the maximum height of fractures was set at $500 \mathrm{~mm}$.

Basic parameters of $\mathrm{T}$ beam are summarized in Table 4.

\subsection{Evaluation of Bending Stiffness}

According to the relationship between the characteristic parameters of crack and the reduction coefficient of bending stiffness of this paper, the bending stiffness can be evaluated. 
Table 4. The basic parameter of $\mathrm{T}$ beam.

\begin{tabular}{cccc}
\hline Parameters & $h / \mathrm{mm}$ & $h_{0} / \mathrm{mm}$ & $f_{d} / \mathrm{MPa}$ \\
\hline Value & 750 & 707.5 & 15.9 \\
\hline
\end{tabular}

$W_{\max }=0.6 \mathrm{~mm}$ substitute into formula (1), it can be got $\beta=0.49$

$H=h_{c r} / h=0.67$, substitute into formula (3), it can be got $\beta=0.667$

So the bending stiffness reduction coefficient $\beta=0.49$. The reduction of bending stiffness is larger, which affects the normal use of the structure. It is consistent with the evaluation results through load test of the real bridge. It shows that the calculation formula in this paper is reliable.

\section{Conclusions}

According to the statistical data of the characteristic parameters of crack of four pieces of model test beams, the relationship between the characteristic parameters of crack and the reduction coefficient of flexural stiffness is established by regression analysis.

The regression equation of the reduction coefficient of stiffness and the maximum width and height of crack is obtained. It is used to evaluate an in-service reinforced concrete girder bridge. The results are consistent with the load test results. It is indicated that the flexural stiffness evaluation method presented in this paper is reliable.

\section{Conflicts of Interest}

The authors declare no conflicts of interest regarding the publication of this paper.

\section{References}

[1] Zhong, M. (2008) Study on Crack of Prestressed Concrete Continuous Box Girder Bridge. Thesis, Southwest Jiaotong University, Chengdu.

[2] Wang, X.Z. (2011) Existing Bridge Condition Assessment Based on Crack Characteristics. Thesis, Chang'an University, Xi'an.

[3] Jefferson, A.D. (2002) Tripartite Cohesive Crack Model. Journal of Engineering Mechanics, 128, 644-653. https://doi.org/10.1061/(ASCE)0733-9399(2002)128:6(644)

[4] Tan, D.L. (2005) The Existing Bridge Assessment Methods Based on Quantitative Statistics Theory Are Discussed. Journal of China \& Foreign Highway, 50, 79-81.

[5] LIU, X.L. (2006) Experimental Study on Evaluation of Bridge Bearing Capacity by Crack Characteristics. Thesis, Northeastern University, Shenyang.

[6] Zhao, Q. (2007) Calculation Theory and Finite Element Analysis of Concrete Member Crack. Thesis, Wuhan University of Technology, Wuhan.

[7] Zhao, J.L. (2006) Study on Bridge Crack Mechanism and Control Countermeasures. Thesis, Chang'an University, Xi'an.

[8] Muttoni, A. and Fernández, R.M. (2007) Concrete Cracking in Tension Members and Application to Deck Slabs of Bridges. Journal of Bridge Engineering, 12, 646-653. 
https://doi.org/10.1061/(ASCE)1084-0702(2007)12:5(646)

[9] Chen, G.M., Chen, J.F. and Teng, J.G. (2012) On the Finite Element Modelling of RC Beams Shear-Strengthened with FRP. Construction and Building Materials, 32, 13-26. https://doi.org/10.1016/j.conbuildmat.2010.11.101

[10] Zhao, Y., HE, S.H. and LI, C.F. (2010) Evaluating System of Bearing Capacity for Existing Cracked Prestressed Concrete Box Girder Based on Crack Feature. Journal of Tongii University (Natural Science Edition), 9, 1271-1275.

[11] Liang, P. and Lou, C.H. (2014) Rapid Evaluation of Load-bearing Capacity of Concrete Beam Bridges Based on Crack Feature Library. China Journal of Highway and Transport, 8, 32-41. 